\begin{tabular}{|c|c|c|}
\hline $\begin{array}{c}\text { Proceeding } \\
\text { SALATIGA }\end{array}$ & $\begin{array}{c}\text { Procember 2021 } \\
\text { 9-ISSN: 2827-9581 } \\
\text { Eebsite: http://conference.iainsalatiga.ac.id/index.php/iciegc }\end{array}$ & Hal. 137-148 \\
\hline
\end{tabular}

\title{
MULTIKULTURALISME DALAM KEHIDUPAN ANTAR UMAT BERAGAMA BERBASIS NILAI KEARIFAN LOCAL (STUDY PADA MASYARAKAT KELURAHAN PASAR UJUNG KABUPATEN KEPAHIANG)
}

\author{
Yulia Gusti $^{1}$, Haris Agustian ${ }^{2}$, Mirza Saraweidi ${ }^{3}$, Sri Kartika ${ }^{4}$, Hendra Harmi ${ }^{5}$ \\ 1,2,3,4,5 IAIN Curup
}

\begin{tabular}{l}
\hline \hline Informasi Artikel \\
\hline Penulis Korespondensi: \\
Yulia Gusti, \\
Email: \\
yuliagusti88@gmail.com
\end{tabular}

\begin{abstract}
Pasar Ujung village is located in Kepahiang Regency, Bengkulu Province which has three religion communities namely Muslim, Christian and Buddhist. Religious diversity in the Pasar Ujung village gives birth to a condition of a multicultural society. This article aims to reveal the role of local wisdom in inter religious life in Pasar Ujung Kepahiang District. This research uses qualitative research methods with a descriptive approach. Based on the results of the study, it was found that there are three values of lokal wisdom that are the glue of the Pasar Ujung village community. The three values of wisdom are mutual help and support, a sense of brotherhood and mutual respect and respect. In addition to the value of local wisdom, there is also the life philosopy of the Pasar Ujung village community. The philoshopy is "Sehasen" which means agreed, aligned, harmonious, safe, and peaceful in determining all policies. The religious diversity in the Pasar Ujung village is the hallnark of the Pasar Ujung village and distinguishes it from other villages.
\end{abstract}

\footnotetext{
Keyword: Local culture, pasar ujung village

ABSTRAK

Kelurahan Pasar Ujung terletak di Kabupaten Kepahiang Provinsi Bengkulu yang memiliki tiga komunitas agama yaitu Muslim, Kristen, dan Budha. Keragaman beragama di Kelurahan Pasar Ujung melahirkan suatu kondisi masyarakat yang multikultur. Artikel ini bertujuan untuk mengungkap peran kearifan lokal dalam kehidupan antar umat beragama di Kelurahan Pasar Ujung Kabupaten Kepahiang. Penelitian ini menggunakan metode penelitian kualitatif dengan pendekatan Deskriptif. Berdasarkan hasil penelitian ditemukan bahwa terdapat tiga nilai kearifan lokal yang menjadi perekat kohesivitas sosial masyarakat Kelurahan Pasar Ujung. Ketiga nilai kearifan tersebut adalah: (1) saling tolong menolong dan mendukung (2) rasa persaudaraan (3) rasa saling menghargai dan mengormati. Selain nilai kearifan terdapat juga falsafah hidup masyarakat kelurahan Pasar Ujung. Falsafah tersebut adalah "Sehasen" yang berarti sepakat, selaras, harmonis, aman dan sentosa dalam menentukan segala kebijakan. Keragaman agama di Kelurahan Pasar Ujung menjadi ciri khas Kelurahan Pasar Ujung dan membedakannya dengan desa lain.
}

Kata kunci: Kearifan lokal, kelurahan pasar ujung 


\section{PENDAHULUAN}

Indonesia adalah realitas kemajemukan, keragaman suku, agama, bahasa, dan budaya yang dapat dijumpai diseluruh penjuru negeri. Dan keragaman ini pula yang menjadi pemersatu bangsa. Kesadaran historis semacam ini menegaskan bahwa kemajemukan sebagai sebuah kenyataan sosiol-kultural bangsa (Maksum, 2011). Kemajemukan masyarakat di Indonesia bukanlah suatu keunikan yang memerlukan perlakuan khusus karena dalam realitas kehidupan tidak ada suatu masyarakat yang benar-benar tunggal (unitary) tanpa ada unsur-unsur perbedaan didalamnya. Kesatuan tersebut justru tercipta karena adanya perbedaan perbedaan didalamnya. Keberagaman merupakan sunnatullah yang harus direnungi dan diyakini setiap umat, kesadaran umat beragama menjadi kunci bagi keberlangsungan dalam menjalankan agamanya masing-masing (Rahman, 2014).

Kemajemukan pada masyarakat dapat dijaga melalui kerukunan. Selama manusia hidup, perbedaan akan selalu ada. Potensi konflik juga selalu terbuka lebar. Hal yang penting untuk dilakukan adalah melakukan usaha dalam bentuk apapun agar keragaman itu bisa menjadi kehidupan yang harmonis. Jika tidak ada usaha secara serius, kehidupan tidak lagi diwarnai dengan keindahan (Naim, 2016). Kerukunan umat beragama merupakan pilar kerukunan nasional dan dinamis harus terus dipelihara dari waktu ke waktu. Kerukunan umat beragama dapat diartikan sebuah keadaan hubungan se sama umat beragama yang dilandasi toleransi, saling pengertian, saling menghormati, menghargai kesetaraan dalam pengamalan ajaran agamanya dan kerja- sama dalam kehidupan bermasyarakat, berbangsa dan bernegara (Hasan, 2013).

Kelurahan Pasar Ujung terletak di Kecamatan Kepahiang Kabupaten Kepahiang, dapat dikatakan sebagai gambaran suatu kemajemukan masyarakat. Kemajemukan masyarakat di kelurahan pasar ujung disebabkan karena terdapat tiga komunitas agama di kelurahan tersebut, yaitu komunitas Muslim, komunitas Kristiani, dan komunitas Budha. Masyarakat Kelurahan Pasar Ujung juga terdiri dari bermacam etnik dan suku seperti cina, batak, rejang, serawai, sunda, padang, Palembang dan jawa. Kemajemukan masyarakat umat beragama tersebut melahirkan suatu kondisi masyarakat yang multikultur. Kelurahan pasar ujung terletak di Kecamatan Kepahiang Kabupaten Kepahiang, terdapat 14 RT (rukun tetangga) dengan jumlah penduduk sekitar 4005 jiwa yang terdiri dari beragam agama. Pemeluk Islam di kelurahan Pasar Ujung sekitar 85\%, Kristen sekitar 10\% dan sisanya adalah pemeluk agama Budha. masyarakat kelurahan Pasar Ujung mampu menerima perbedaan dan hidup rukun berdampingan. Kehidupan harmonis berdasar nilai kearifan 
lokal memunculkan interaksi sosial yang khas berbeda dengan Kelurahan lain di kabupaten kepahiang.

Dapat dijumpai di Kelurahan Pasar Ujung adanya makam yang digunakan dua pemeluk agama yaitu makam kristiani dan makam budha sebagai makam bersama oleh masyarakat setempat secara turun temurun. Masyarakat Kelurahan Pasar Ujung tidak mempermasalahkan jika kompleks pemakaman dijadikan milik bersama. Selain itu simbol realitas keberagaman agama juga dijumpai dikelurahan pasar ujung. Seperti terdapat komplek tempat ibadah yang mana dalam satu lokasi yang berdekatan terdapat tiga tempat ibadah lintas agama yaitu masjid, gereja katolik dan gereja protestan.

Keberagaman dan kemajemukan yang terjadi di Kelurahan Pasar Ujung dapat dijadikan model masyarakat multikultural yang hidup harmonis berdampingan antar umat beragama. Kondisi seperti ini menjadi keunikan tersendiri dan simbol identitas masyarakat Kelurahan Pasar Ujung sebagai masyarakat plural. Dengan adanya keberagaman agama yang ada di Kelurahan Pasar Ujung, tidak menjadi sumber pemecah, namun menjadi pemersatu masyarakat. Keberagaman dan kearifan lokal adalah satu hal yang saling berkaitan, karena dalam keberagaman dapat disatukan dari kebiasaan yang telah ada pada masyarakat itu sendiri. Nugroho (2019) Paham tentang kearifan lokal (local wisdom) menjadi sebuah pandangan hidup dan pengetahuan serta sebagai strategi kehidupan yang berwujud aktifitas yang dilakukan oleh masyarakat lokal dalam memenuhi kebutuhan mereka.

Beberapa kajian yang terkait dengan multikulturalisme dalam kehidupan antar umat beragama berbasis nilai kearifan lokal sudah dikaji oleh peneliti terdahulu misalnya penelitian yang sudah dilakukan oleh Robert Siburian yang berjudul Multikulturalisme: Belajar dari masyarakat Pedesaan. penelitian ini memaparkan bahwa Implementasi Nilainilai multikulturalisme itu telah diterapkan sejak pemerintah Indonesia menempatkan mereka di lokasi yang baru sebagai peserta transmigrasi. Tokoh dari setiap kelompok masyarakat dan agama memahami perbedaan itu, sehingga mereka mendorong setiap kelompok agar dapat hidup bersama. Meskipun masyarakat di Desa Kerta Buana tidak memahami konsep multikulturalisme, secara tidak sadar bahwa nilai-nilai multikulturalisme itu sudah mereka aplikasikan dalam kehidupan sehari-hari (Siburian, 2017).

Selanjutnya penelitian yang dilakukan oleh Nur Syamsiyah yang berjudul Multikulturalisme Masyarakat Perkotaan (Studi Tentang Integrasi Sosial Antar Etnis di Kelurahan Nyamplungan Kecamatan Pabean Cantikan Kota Surabaya). Penelitian ini 
mengungkapkan bahwa Kesadaran multikultural menjadi salah satu unsur yang cukup penting dalam upaya mewujudkan integrasi sosial masyarakat. Terdapat enam indikator yang menjadi syarat terwujudnya integrasi sosial, diantaranya: 1) Tidak mempermasalahkan adanya perbedaan; 2) Adanya kemauan untuk memberikan toleransi; 3) munculnya hibridasi budaya dan identitas bersama; 4) Adanya kesediaan untuk bekerjasama; 5) Adanya kemauan untuk bermusyawarah dan 6) berkembangnya solidaritas sosial (Syamsiyah, 2018).

Sukmayadi juga menjelaskan dalam penelitiannya yang berjudul Nilai-Nilai Kearifan Lokal Dalam Pandangan Hidup Masyarakat Adat Kampung Kuta. Nilai-nilai karakter yang tercermin dalam pandangan hidup masyarakat adat Kampung Kuta adalah nilai ikhlas, taat, visioner, bertanggung jawab, pengabdian, setia, simpati, empati, kasih sayang, toleran, rela berkorban, mengabdi, beriman, bertaqwa, sederhana, rendah hati, menghargai kesehatan, bijaksana, dan berfikir konstruktif (Sukmayadi, 2018). Artinya bahwa nilai kearifan lokal adalah yang menjadi perekat masyarakat multikultural.

Penelitian itu bertujuan untuk mendiskripsikan kondisi keberagaman umat beragama di kelurahan Pasar Ujung Serta untuk mendeskripsikan strategi memasyarakatkan nilai kearifan lokal bagi kehidupan masyarakat lintas agama di kelurahan Pasar Ujung Kecamatan Kepahiang Kabupaten Kepahiang. Penelitian ini didasarkan beberapa alasan, diantaranya adalah di kelurahan Pasar Ujung terdapat tiga komunitas agama yang mampu hidup rukun dan berdampingan tanpa adanya konflik antar umat beragama. Di tengah melunturnya toleransi umat beragama, masyarakat kelurahan Pasar Ujung konsisten menjaga kerukunan dengan landasan nilai-nilai kearifan lokal yang ada. Kedua karena keragaman budaya dan agama yang ada di kelurahan Pasar Ujung yaitu Islam, Kristen dan Budha. Setiap agama yang ada di Kelurahan Pasar Ujung membawa masing-masing budayanya seiring dengan ritual keagamaan masing-masing agama. Hal ini memperkaya tradisi yang ada di kelurahan Pasar Ujung. Masyarakat antar umat beragama saling menghormati, saling berbagi, dan terlibat dalam perayaan keagamaan, namun bukan dalam kegiatan peribadatan. Ketiga, kelurahan Pasar Ujung dapat dijadikan rujukan dalam praktik toleransi kehidupan antar umat beragama ditengah isu fanatisme keagamaan yang saling mengklaim kebenaran atas agamanya, dan maraknya politik identitas yang dapat menghancurkan semangat kebhinnekaan. 


\section{METODE}

Penelitian ini menggunakan jenis penelitian kualitatif dengan metode deskriftif. Penelitian deskriptif kualitatif dirancang untuk mengumpulkan informasi tentang keadaankeadaan nyata sekarang yang sementara berlangsung. penelitian deskriptif kualitatif adalah suatu metode dalam meneliti status sekelompok manusia, suatu objek dengan tujuan membuat deskriptif, gambaran atau lukisan secara sistematis, faktual dan akurat mengenai fakta-fakta atau fenomena yang diselidik (Sevilla, 1993).

\section{HASIL DAN BAHASAN}

\section{Multikulturalisme dalam kehidupan umat beragama berbasis nilai kearifan lokal di Kelurahan Pasar Ujung Kabupaten Kepahiang}

Kelurahan Pasar Ujung merupakan masyarakat multikultur yang dipenuhi berbagai agama, suku dan ras yang hidup saling berdampingan. Parekh (2001) menjelaskan bahwa multikulturalisme erat kaitannya dengan keberadaan masyarakat multikultural. Masyarakat multikultural dapat diartikan sebagai kelompok manusia yang tinggal dan hidup menetap di suatu tempat yang memiliki kebudayaan dan ciri khas tersendiri yang mampu membedakan antara satu masyarakat dengan masyarakat lainnya (Wiyanto, 2012). Wirma (2017) menjelaskan bahwa Multikultural merupakan keberagaman masyarakat namun hidup bersatu dalam kehidupan sosial tanpa adanya intimidasi dari kelompok yang besar terhadap kelompok yang minoritas. Sementara itu Harmi (2020) mengatakan bahwa multikulturalisme berisi seperangkat kepercayaan dan pandangan yang mendalam terhadap perbedaan dan menerimanya sebagai sesuatu yang alamiah dan bersifat naturalistik. Dengan asumsi bahwa manusia tidak dapat hidup dalam entitas tunggal atau menutup mata dari perbedaan.

Multikulturalisme dalam masyarakat Kelurahan Pasar Ujung terlihat pada kondisi masyarakat di Kelurahan Pasar Ujung dimana Kelurahan Pasar ujung memiliki luas wilayah sekitar 8,6 km2. Luas wilayah ini dihuni oleh 4005 jiwa yang terbagi menjadi 14 RT dan 5 RW. Mata pencahrian masyarakat kelurahan Pasar Ujung relatif sama dengan kelurahan lain yaitu $75 \%$ adalah petani, $25 \%$ adalah pedagang dan $10 \%$ adalah PNS. Adapun suku dan etnis masyarakat kelurahan pasar ujung adalah rejang, cina, serawai, jawa, padang, Palembang, batak dan sunda. Jumlah tempat ibadah di kelurahan Pasar Ujung per-31 Desember 2020 masjid berjumlah 5, mushola 1 dan gereja 3. Perkiraan terkini penduduk 
muslim sekitar 85\%, Kristen 10\%, dan sisanya Budha. Mereka hidup berdampingan secara harmonis dan ini sudah berlangsung sejak lama.

Sumbulah dan Nurjanah (2013) mengatakan bahwa kerukunan umat beragama terjalin ketika memenuhi beberapa cara, yaitu: pertama, adanya dialog dan kerjasama antar umat beragama. Dengan kerjasama dan dialog dalam pertemuan para pemuka agama dapat memberikan dampak positif bagi tiap-tiap agama. Bukan hanya dialog, akan tetapi kerjasama dapat menyelesaikan permasalahan kemanusiaan yang terjadi dalam kehidupan sosial. Sebagaimana menurut Catto (2017) berpendapat bahwa kurangnya kepedulian dan keterlibatan dapat menjadi suatu awal munculnya konflik dan terjadinya ketegangan dalam kehidupan masyarakat yang plural. Kedua, membalas perbuatan buruk dengan kebaikan. Hal sekecil ini dapat dapat menimbulkan rasa kerukunan umat beragama, karena ajaran dari tiap-tiap agama mengajarkan sesuatu yang baik dan tanpa adanya dendam terhadap umat beragama lain. Ketiga, pendekatan wilayah dapat menumbuhkan kerukunan umat beragama dengan adanya partisipasi dalam undangan dari setiap kegiatan yang dilakukan oleh agama lain. Silahturahmi antara masyarakat umat beragama dilakukan dalam kegiatan seperti Hari Raya besar Idul Fitri, Natal dan Paskah. Keempat, selalu menghargai agama umat lain. dalam setiap agama mengajarkan untuk selalu menghargai agama umat lain.

Dengan adanya nilai keseimbangan, keadilan, kehormatan, dan perdamaian yang dianut oleh setiap pemeluk agama maka terciptalah Kerukunan dalam kehidupan umat beragama (Syihab \& Muhamad, 2017). Kerukunan umat beragama terbentuk juga karena adanya interaksi sesuai dengan norma yang berlaku. Interaksi tersebut mengedepankan rasa hormat, rendah hati, kerjasama terhadap sesama umat beragama maupun sesama umat beragama lain dengan tujuan membangun kesejahteraan dan perdamaian dalam masyarakat. Kerukunan umat beragama terjalin ketika adanya pemahaman individu dalam kehidupan sehari-hari (Khambali, 2017).

Sementara itu kearifan lokal didefinisikan sebagai kebenaran yang telah mentradisi atau ajeg dalam suatu daerah (Gobyah, 2009). Ife (2002) menyatakan bahwa kearifan lokal merupakan nilai- nilai yang diciptakan, dikembangkan dan dipertahankan dalam masyarakat lokal dan karena kemampuannya untuk bertahan dan menjadi pedoman hidup masyarakatnya. Kearifan lokal menjadi pengetahuan yang lahir dari rahim masyarakat, tumbuh dan berkembang juga bersama masyarakat dalam periode yang panjang sehingga menjadi kultur bersama yang dimiliki masyarakat (Ridwan, 2007). 
John Haba (dalam Abdullah dkk, 2008) memberikan lima fungsi kearifan lokal. Pertama, kearifan lokal merupakan penanda (signifer) komunitas atas kehidupan yang harmonis dan damai yang merepresentasikan adanya sebuah peradaban. Kedua, kearifan lokal menjadi tempat bertemunya banyak elemen yang menjadi perekat lintas agama, kepercayaan, dan warga. Ketiga, kearifan lokal sebagai resolusi konflik yang tidak bersifat koersif dan struktural, tapi menyediakan arena perundingan yang tidak kaku, sejajar, dan kultural. Keempat, kearifan lokal menjadi sumber inspirasi kebersamaan, memupuk solidaritas, serta menangkal hal-hal yang merusak solidaritas komunal dari komunitas yang sudah terintegrasi. Kelima, kearifan lokal sebagai media transformasi sosial yang asimetris dalam jejaring masyarakat.

Kearifan lokal merupakan identitas (cultural identity) yang lahir dari konstruksi wacana tentang dunia yang dialami masyarakat yang dibuktikan dengan artikulasi bahasa, baik menggunakan medium tuturan maupun tulisan terkait peran dan hubungan antar sesama dalam masyarakat. Ia harus dipahami sebagai sesuatu yang diciptakan oleh kesadaran masyarakat sendiri dan bukan ditemukan (Barker, 2005). Pada umumnya, kearifan lokal tertanam di masyarakat pedesaan khususnya di Jawa, misalnya tradisi slametan, tingkeban, dan bersih desa (Sumbulah, 2012). Kearifan lokal berperan penting dalam menyelesaikan masalah-masalah yang terjadi dalam masyarakat, mencakup masalah ekonomi, pemerintahan khususnya dalam penataan ruang, pendidikan, pengurangan risiko bencana, dan konflik bernuansa agama (Khambali, 2017).

Untuk mengetahui nilai - nilai kearifan lokal yang ada di Kelurahan Pasar Ujung maka peneliti sudah mewancarai 6 orang informan yaitu 3 orang laki- laki dan 3 orang perempuan dengan agama dan suku yang berbeda. Adapun identitas informan dapat dilihat pada tabel 1.

Berdasarkan hasil observasi dan wawancara yang sudah peneliti lakukan ditemukan bahwa adanya falsafah yang menjadi pegangan bagi masyarakat di Kelurahan Pasar Ujung. Falsafah tersebut adalah "Sehasen" yang memiliki arti bahwa sepakat, selaras, harmonis, dalam menentukan segala kebijakan. Seorang informan (SA) beliau adalah ketua RT 04 di Kelurahan Pasar Ujung mengatakan bahwa "tidak ada falsafah lainnya yang ada di Kelurahan Pasar Ujung. Falsafahnya satu yang digunakan yaitu 'Sehasen" masyarakat Kelurahan Pasar Ujung selalu memegang teguh falsafah ini sehingga tercipta kedamaian dan keharmonisan di lingkungan sosial masyarakat di Kelurahan Pasar Ujung”. 
Tabel 1 Identitas Informan

\begin{tabular}{lllll}
\hline No & \multicolumn{1}{c}{ Nama } & \multicolumn{1}{c}{ Agama } & Etnis/Suku & Jenis Kelamin \\
\hline 1. & Nazarrudin & Islam & Padang & Laki - laki \\
\hline 2. & Neli Kendari & Islam & Serawai & Perempuan \\
\hline 3. & Andi Manurung & Kristen & Batak & Laki - laki \\
\hline 4 & Lina Mariance Hutapea & Kristen & Batak & Perempuan \\
\hline 5. & Cici Jia Li & Budha & Cina & Perempuan \\
\hline 6. & Saiful Amri & Islam & Jawa & Laki - laki \\
\hline
\end{tabular}

Selain falsafah diatas menjadi pegangan pada masyarakat diKelurahan Pasar Ujung untuk hidup rukun dalam beragama, adanya nilai-nilai kearifan lokal yang mendukung sehingga kerukunan tetap terjaga. Pertama yaitu adanya rasa saling tolong - menolong dan mendukung. Sikap saling tolong - menolong dan mendukung sudah tercipta dalam kehidupan masyarakat kelurahan Pasar Ujung melalui beberapa kegiatan yang sudah dilakukan dari tahun ke tahun. Seperti yang dikatakan oleh informan (CJ) “dalam kegiatan kerja bakti di Kelurahan Pasar Ujung sering dilakukan pembersihan tempat ibadah tiap-tiap agama seperti gereja dan masjid. semua umat beragama bersama-sama terlibat dari anak anak perangkat desa dan tokoh masyarakat saling tolong - menolong penuh semangat tanpa ada rasa perbedaan dalam kegiatan kerja bakti”. Hasil wawancara ini menjelaskan bahwa Kegiatan sederhana seperti kerja bakti yang dilaksanakan di Kelurahan Pasar Ujung sangat besar dampaknya dengan pembauran antar agama dan interaksi antarsesama umat maupun para tokoh sehingga menciptakan kebersamaan karena semua agama terlibat dalam hal tersebut. Hal ini senada dengan teori Alwasih, et al (2009) menjelaskan bahwa kearifan lokal merupakan suatu kebiasaan yang dilakukan sudah bertahun tahun lamanya oleh induvidu atau masyaraka melalui pengalaman dan bertahan hingga saat ini.

Kedua adanya rasa persaudaraan. Perilaku yang mewujudkan rasa persaudaraan adalah disaat hari raya besar umat islam yaitu idhul fitri, maka saudara umat kristen ikut bersilahturahmi berjabat tangan kepada tetangga yang beragama muslim. Begitupun sebaliknya ketika hari raya natal, umat islam datang ke rumah tetangganya yang merayakan hari natal dan mengucapkan selamat natal. Hal ini seperti yang diceritakan oleh informan (NK) "ketika kami merayakan hari raya idul fitri maka mereka (Kristen) datang kerumah kami dan mengucapkan selamat hari raya Idul fitri. Begitu juga sebaliknya jika tetangga kami merayakan hari natal maka kami juga mengucapakan selamat natal kepada mereka dan kadang kami mendapatkankan ampau yang dibagikan mereka"

Bentuk rasa persaudaraan lainnya di Kelurahan Pasar Ujung adalah seperti yang dikatakan oleh informan $(\mathrm{N})$ yang merupakan tokoh masyarakat dikelurahan Pasar Ujung 
beliau mengatakan bahwa : "disebelah rumah saya adalah orang beragama budha ketika beliau nya sakit maka kami datang kerumah mereka melihat dan mengunjungi tetangga kami yang sakit tersebut" lanjut kata beliau :'kami sering berkumpul bersama, jika ada sedikit rezeki kamipun terbiasa saling berbagi”. Hal ini senada dengan yang disampaikan oleh Purbasari (2019) bahwa interaksi sosial dapat menumbuhkan dan membangun rasa persaudaraan antar sesama dan dapat meminimalisir konflik dan kesenjangan sosial karena adanya sikap keterbukaan antar sesama.

Ketiga adanya rasa saling menghargai dan menghormati. Hal ini ditunjukan dengan Acara pernikahan. Siapapun yang memiliki acara pernikahan selalu melibatkan dan mengundang tetangga yang bebeda agama, bahkan meskipun di dalamnya ada penceramah dari yang seiman. Namun, yang hadir dari beda agama tetap menyimak acara sampai selesai. Seperti yang dikatakan oleh Informan (LM) menyatakan bahwa: "ada salah satu warga yang punya hajat, misalnya nikahan. Kebetulan yang punya hajat orang islam, sebelum hari pelaksanaan biasanya ada kenduri mengumpulkan masyarakat kemudian ada acara ceramah agama, kalau yang punya hajat muslim ya ngundang kyai dengan mengumpulkan masyarakat termasuk saya lintas agama"

Selanjutnya pada saat adanya musibah yaitu kematian. Apabila ada warga yang meninggal, semua warga ikut melayat terlepas yang meninggal itu beda agama meskipun proses ritualnya sesuai agama masing-masing. Informan (AM) mengatakan: "seperti hajatan atau ada yang terkena musibah meninggal ya berlaku secara umum seperti masyarakat lain. Kalau Islam atau Kristen yang meninggal, takziyah juga membaur menjadi satu, tapi proses ritualnya masing-masing”. Dalam Tahlilan untuk mendoakan orang yang telah meninggal, khususnya Islam, maka muslim mengundang tetangganya yang non-muslim, meskipun kehadiran mereka sebagai pemenuhan undangan dan ikut mendoakan, tetapi bukan tahlilan. Sebaliknya, apabila orang yang meninggal beragama Budha, warga Islam dan Kristen juga diundang mengikuti upacara, meskipun yang memimpin doa pemimpin agama Budha. Informan menyampaikan: "kalau disini tahlil itu ada orang meninggal, karena di sini ada 3 agama, kalau misal Islam yang meninggal nanti ada anggota tahlilnya sendiri. Tapi kalau agama lain walaupun diundang ya cuma ikut acara sampai selesai."

Dari hasil wawancara diketahui bahwa masyarakat kelurahan Pasar Ujung yang dalam keseharian saling berinteraksi baik berinteraksi sesama umat beragama maupun berinteraksi dengan agama lain yang mengedepankan toleransi, saling menghormati, menghargai kesetaraan dan kerja sama dalam kehidupan bermasyarakat, berbangsa, dan bernegara di 
dalam Negara Kesatuan Republik Indonesia berdasarkan Pancasila dan Undang-Undang Dasar Negara Republik Indonesia tahun 1945. Budaya seperti ini menjadi kekuatan besar yang harus di wariskan kepada anak muda dan kearifan-kearifan dalam beriman dari setiap tokoh agama antar umat beragama harus terjalin terus menerus. Hartini (2018) mengatakan bahwa terlepas dari konseling Kearifan memberikan pandangan komprehensif yang efektif dalam hubungannya dengan budaya, mampu berfikir dialektis, melakukan metakognisi, meninjau hubungan antarpribadi secara mendalam dan empati.

Perbedaan dalam hal keyakinan tidak sampai memicu perpecahan dan batasan dalam pergaulan antara umat beragama. Dalam agama mangajarkan untuk saling menghormati agama lain, mewujudkan kerukunan umat beragama dan menambah persaudaraan antara penganut agama. Hal ini senada dengan teorinya Imron dan Hidayat (2013) mengatakan bahwa kearifan lokal dapat mewujudkan kerukunan umat beragama ketika dalam suatu masyarakat warga harus saling akrab, akur dalam kebersamaan di masyarakat sosial. Masyarakat kelurahan Pasar Ujung selalu menumbuhkan rasa persaudaraan dan meninggalkan perbedaan untuk mencapai satu tujuan yang sama yaitu kehidupan yang harmonis. Hal ini sudah dilaksanakan dalam kehidupan nyata seperti kegiatan hari raya adanya partisipasi dari agama lain yang terlibat untuk membantu dalam hal tersebut, sehingga mencerminkan rasa kebersaman yang kuat antar mereka. Adanya rasa senasib, kebersamaan, dan sepenanggungan tanpa memandang agama, etnis, dan kelas sosial.

\section{KESIMPULAN}

Multikulturalisme dalam kehidupan antar umat beragama pada masyarakat kelurahan Pasar Ujung telah terjadi lama dan dibentuk serta dikembangkan melalui budaya yang berkembang di masyarakat, yang dapat disebut sebagai kearifan lokal. kearifan lokal di Kelurahan Pasar Ujung antara lain sebagai berikut: 1) saling tolong menolong dan mendukung, 2) rasa persaudaraan dan 3) rasa saling menghargai dan mengormati. Adapun pandangan hidup atau falsafah masyarakat kelurahan Pasar Ujung adalah "Sehasen" yang berarti sepakat, selaras, harmonis, aman dan sentosa dalam menentukan segala kebijakan tanpa memandang agama, suku maupun ras. Kearifan lokal di kelurahan Pasar Ujung berfungsi dalam beberapa hal. Pertama, sebagai titik simpul bertemunya banyak elemen, perekat lintas agama, kepercayaan, dan warga. Kedua, sebagai resolusi konflik yang tidak bersifat koersif dan struktural. Ketiga, menjadi sumber inspirasi kebersamaan, memupuk solidaritas, serta menangkal hal-hal yang merusak solidaritas komunal dari komunitas yang sudah terintegrasi. Berpegang pada kearifan lokal ini masyarakat kelurahan Pasar Ujung 
mencapai idealisme masyarakat toleran di mana warganya yang berlainan keyakinan dan agama saling menyayangi, saling menghormati, dan saling memperkuat satu sama lainnya.

\section{DAFTAR RUJUKAN}

Adullah, I. (2008). Agama dan Kearifan Lokal dalam Tantangan Global. Yogyakarta: Pustaka Pelajar.

Alwasih, C. (2009). Etnopedagogi: Landasan Praktek Pendidikan Dan Pendidikan Guru. Bandung: Kiblat Universitas Pendidikan Indonesia.

Azizah, I., Kholis, N., Huda, N. (2020). Model Pluralisme Agama Berbasis Kearifan Lokal 'Desa Pancasila' Di Lamongan. Fikrah, 8(2), 277-294.

Barker, C. (2005). Cultural Studies. Yogyakarta: Kreasi Wacana.

Catto, R. (2017). Religious Indifference New Perspectives From Studies On Secularization And Nonreligion. Gewerbestrasse: The registered company address. DOI 10.1007/978-3-319-48476-1

Gobyah, I.K. (2009). Berpijak Pada Kearifan Lokal. Retrieved November 20, 2021, from website balipos: www.balipos.co.id

Harmi, H., Jannah, N., and Sholihin, M. (2020). Kecerdasan Kultural Siswa Muslim dan Non-Muslim Di Kota Curup: Sebuah Eksplorasi Kualitatif. Belajea: Jurnal Pendidikan Islam, 5(1), 93 - 112.

Hartini. (2018). Multicultural Considerations In Group Playtherapy. Paper presented at Seminar Nasional BK Perguruan Tinggi, UPI, Bandung, 6 April 2018 (pp. 197-210). Bandung: UPT-BKPK.

Hasan, M.H.A. (2013). Merajut Kerukunan Dalam Keragaman Agama DI Indonesia (Perspektif Nilai-Nilai Al-Quran). Profetika: Jurnal Studi Islam,14(1), 66-77.

Ife, J. (2002). Community Development, Creating Community Alternatives. Australia: Longman.

Imron, A. \& Hidayat, A. (2013). Kekuatan Agama Dan Kearifan Lokal Dalam Proses Kebangkitan Masyarakat Yogyakarta Pascagempa. Jurnal Esensia, XIV(1) 103-130.

Khambali, M. K. (2017). Al-Wasatiyyah In The Practice Of Religious Tolerance Among The Families Of New Muslims In Sustaining A Well-Being Society. Journal Humanomics, 3(33), 211-220.

Maksum, A. (2011). Pluralisme dan Multikulturalisme Paradigma Baru Pendidikan Agama Islam di Indonesia (Pertama). Yogyakarta: Aditya Media Publishing.

Mudzhar, M. A. (2010). Sosialisasi PBM dan Tanya Jawabnya. Jakarta: Badan Litbang dan Diklat Kementerian Agama Republik Indonesia.

Naim, N. (2016). Membangun Kerukunan Masyarakat Multikultural. Harmoni, 15(1), 203213.

Parekh, B. (2001). Rethinking Multikulturalism: Cultural Diversity and Political Theory.

Cambridge: Harvard University Press

Purbasari, A. V. (2019). Interaksi Sosial Etnis Cina-Jawa Kota Surakarta. Jurnal Antropologi: Isu-Isu Sosial Budaya, 21(1), 1-9.

Rahman, M.S. (2014). Islam dan Pluralisme. Fikrah: Jurnal Ilmu Aqidah Dan Studi Keagamaan, 2(1), 401-418.

Ridwan, N.A. (2007). Landasan Keilmuan Kearifan Lokal. IBDA: Jurnal Studi Islam dan Budaya, 5(1), 27-38.

Sevilla, Consuelo G, (1993). Pengantar Metode Penelitian. Jakarta: UI Press 
Siburian, R. (2017). Multikulturalisme: Belajar Dari Masyarakat Perdesaan. Masyarakat Indonesia: Jurnal Ilmu-Ilmu Sosial Indonesia, 43(2), 207-232.

Sukmayadi, T. (2018). Nilai-Nilai Kearifan Lokal Dalam Pandangan Hidup Masyarakat Adat Kampung Kuta. Jurnal Pancasila Dan Kewarganegaraan, 3(1), 19-29.

Sumbulah, U. (2012). Islam Jawa Dan Akulturasi Budaya: Karakteristik, Variasi dan Ketaatan Ekspresif. El-Harakah, 14(1), 51-68

Sumbulah, U., \& Nurjanah (2013). Pluralisme Agama Makna Dan Lokalitas Pola Kerukunan Antarumat Beragama. Malang: UIN-Maliki Press.

Syamsiyah, N. (2018). Multikulturalisme Masyarakat Perkotaan (Studi Tentang Integrasi Sosial Antar Etnis di Kelurahan Nyamplungan, Kecamatan Pabean Cantikan, Kota Surabaya). (Unpublished Thesis) Universitas Airlangga, Surabaya, Indonesia.

Syihab, H. A., \& Muhamad. A. (2017). Reviving The Wasatiyyah Values For InterReligious Harmony In Plural Societies. Jurnal Al-Tamaddun, 12(2), 13-24.

Wirman. (2017). Plurality In The Context Of Religious Harmony. Journal Of Humanities And Social Science, 11(22), 25-31.

Wiyanto. (20112). Implementasi Nilai-Nilai Multikultural Pada Sekolahmulti-Etnik. Journal of Ecodunamika, 53(9), 1689-1699. 